\title{
Mapping subglacial surfaces of temperate valley glaciers by two-pass migration of a radio-echo sounding survey
}

\author{
B. C. Welch, ${ }^{1, *}$ W.T. Pfeffer, ${ }^{1}$ J.T. Harper, ${ }^{2}$ N. F. Humphrey ${ }^{2}$ \\ ${ }^{1}$ Institute of Arctic and Alpine Research, University of Colorado, Boulder, Colorado 80309-0450, U.S.A. \\ ${ }^{2}$ Department of Geology and Geophysics, P.O. Box 3006, University of Wyoming, Laramie, Wyoming 82071-3006, U.S.A.
}

\begin{abstract}
High-resolution maps of the glacier bed are developed through a pseudothree-dimensional migration of a dense array of radio-echo sounding profiles. Resolution of three-dimensional maps of subglacial surfaces is determined by the radio-echo sounding wavelength, data spacing in the field, and migration. Based on synthetic radio-echo sounding profile experiments, the maximum resolution of the final map cannot exceed one half-wavelength. A methodology of field and processing techniques is outlined to develop a maximum-resolution map of the glacier bed. The field and processing techniques are used to develop a map of the glacier bed below part of Worthington Glacier, a temperate valley glacier in south-central Alaska. The field techniques and the processing steps used on the glacier result in a map of $20 \mathrm{~m} \times 20 \mathrm{~m}$ resolution.
\end{abstract}

\section{INTRODUCTION}

A radio-echo sounding survey of 18 cross-glacier profiles was recorded on Worthington Glacier using a $5 \mathrm{MHz}$ pulse echo system which has a $33.8 \mathrm{~m}$ wavelength $\left(\right.$ a $169 \mathrm{~m} \mu \mathrm{s}^{-1}$ wave-propagation velocity in ice). The radio-echo sounding transmitter specifications are described in Narod and Clarke (1994) and the profiles were recorded onto a laptop computer via a portable digital oscilloscope. The profiles were arranged to make an orthogonal grid of traces spaced every $5 \mathrm{~m}$ across the glacier and $20 \mathrm{~m}$ along the glacier flowline. The recorded profiles were processed using standard reflection seismic routines adapted for use with radio-echo sounding data. The three-dimensional nature of the glacier bed was interpreted from the raw radio-echo sounding data through two-pass two-dimensional migration which is a simulation of true three-dimensional migration.

Seismic reflection techniques including two-dimensional migration have been successfully adapted to process radio-echo sounding profiles for a variety of applications and environments (Harrison, 1970; Björnsson, 1981; Brown and others 1986; Jacobel and others, 1993; Arcone and others, 1995; Björnsson and others, 1996). Through this study it became clear that the final resolution of a subglacial bedrock map recovered from radio-echo sounding is determined not only by the wavelength of the system, but also by data spacing in the field and the migration routines. These observations have led to a recommended set of field and processing techniques that will maximize the resolution of a three-dimensional radio-echo sounding survey.

\footnotetext{
* Present address: Department of Geology and Geophysics, P.O. Box 3006, University of Wyoming, Laramie, Wyoming 82071-3006, U.S.A.
}

\section{RADIO-ECHO SOUNDING GEOMETRY AND MIGRATION}

Comprehensive reviews of the principles of radar signal propagation and reflection can be found in Robin and others (1969), Smith and Evans (1972) and Bogorodsky and others (1985). It has been shown that due to signal scattering due to free water in temperate ice, $5 \mathrm{MHz}$ is the effective radio-echo sounding frequency for temperate glaciers (Smith and Evans, 1972; Watts and England, 1976). It is assumed here that the wavefronts of transmitted and reflected signals propagate spherically (no propagationvelocity variations within the ice). The lobes of high amplitude along the wavefront that are associated with dipole antennas are ignored (Arcone and others, 1995).

The reflection of radio waves by a subglacial surface will be recorded by the radio-echo sounding system only if the reflected energy is greater than the sensitivity of the receiver. Furthermore, the reflector can be identified only if it exceeds the signal-to-noise ratio (Yilmaz, 1987). The sourcesignal strength is dispersed radially throughout the wavefront as the wave propagates through the glacier (Robin and others, 1969; Yilmaz, 1987). The source signal is also attenuated due to both the dielectric properties of ice and scattering by small water pockets (Robin and others, 1969; Smith and Evans, 1972; Watts and England, 1976). The signal is reflected at an interface of materials of differing electrical impedance (such as the interface between ice and rock). A certain amount of energy will be transmitted through the interface and some will be reflected back toward the glacier surface. The strength of the reflected signal depends on the angle of incidence at the interface as well as the dielectric contrast between the materials on either side of the interface (Robin and others, 1969; Smith and Evans, 1972). The reflected signal will be further scattered and attenuated as it propagates to the receiver, where it will be recorded if the strength is greater than the signal-to-noise ratio of the recei- 
ver (Robin and others, 1969; Smith and Evans, 1972; Watts and England, 1976).

Recorded radio-echo sounding traces are commonly plotted in the manner of seismic data where the trace location is plotted against the travel time of the signal. The amplitude of the recorded signal is plotted either as a line ("wiggle") plot or as a gray scale. This seismic plotting convention, also known as the imaging principle, tacitly assumes that all reflectors are located vertically beneath the trace location (Yilmaz, 1987). For extremely deep or flat reflecting surfaces (such as continental ice sheets or marine seismics), the assumptions of the imaging principle hold. However, for steep-walled valley glaciers, the three-dimensional propagation of the wavefront can reflect off surfaces that are not directly below the transmitter. Figure 1 shows how the imaging principle can lead to inaccurate interpretations of radio-echo sounding data from a valley glacier. Reflection 2 is directly below the trace location and is plotted correctly by the imaging principle. Reflections 1 and 4 are along the profile, but are plotted by the imaging principle as though they were directly below the trace location. Note that the radial distance to reflector 1 is shorter than the distance to reflector 2. Reflector 3 does not lie along the profile plane, but is still recorded and plotted by the imaging principle.

Migration used in seismic processing uses the data of adjacent traces to alter the recorded data so that the imaging principle better represents the actual locations and slopes of the reflecting surfaces. In effect, migration focuses the omnidirectional transmitted radar signal so that each trace plotted by the imaging principle shows only the reflectors located vertically below the trace surface location (Chun and Jacewitz, 1981; Claerbout, 1985; Yilmaz, 1987). The migration routine used in this paper is a frequency-wavenumber routine that is effective for single-velocity systems (the signal travels only through ice) where steep reflector slopes are expected, such as valley walls (Chun and Jacewitz, 1981; Yilmaz, 1987; Cohen and Stockwell, 1996). The frequencywavenumber routine uses the entire digitally recorded dataset so that the results are not biased by pre-migration interpretation of reflectors (Yilmaz, 1987).

\section{DETECTION VS RESOLUTION}

The terms detection and resolution are often given various connotations in both seismic and glaciology literature. For the purposes of this paper, the following definitions will be used. Detection is simply the ability of a radio-echo sounding device to record the energy reflected by an interface. This means that the reflected signal strength exceeds the sensitivity of the recording device, despite losses due to signal dissipation, scattering, attenuation and reflection (Robin and others, 1969; Smith and Evans, 1972).

Resolution is the ability to interpret accurately the shape, slope and size of a reflecting surface once it has been detected. Data spacing is a major factor controlling resolution since reflector dimensions and slopes can be misinterpreted if the data spacing is overly large. In order to avoid such spatial aliasing, traces should be less than one quarterwavelength $(\lambda / 4)$ apart, and for three-dimensional radioecho sounding surveys, profiles should also be less than $\lambda / 4$ apart (Yilmaz, 1987). Where spatial aliasing has been avoided (trace profile spacing is less than $\lambda / 4$ ), resolution is a function of the transmitted signal wavelength which depends on the transmitted frequency and wave velocity in ice (Robin and others, 1969; Yilmaz, 1987).

\section{PRE- AND POST-MIGRATION RESOLUTION}

Where spatial aliasing has been avoided, pre-migration resolution of reflecting surfaces is a function of radio-wave propagation and reflection. Robin and others (1969) and Yilmaz (1987) demonstrated the development of the Fresnel zone as a wave encounters a polished planar reflecting surface at a given distance from the transmitter. The first Fresnel zone describes the area of the reflecting surface that contributes to a single reflection of a single trace as shown below:

$$
r=\sqrt{\frac{\lambda z}{2}+\frac{\lambda^{2}}{16}}
$$

where $r$ is the radius of the first Fresnel zone, $\lambda$ is wavelength, and $z$ is depth below ice surface (Robin and others, 1969; Yilmaz, 1987). Energy reflected from any number of surfaces within the Fresnel zone will contribute to a single peak that is recorded by the radio-echo sounding system. The single peak cannot be broken down into the individual components contributed by the multiple reflecting surfaces within the Fresnel zone. Therefore, while a feature smaller than the Fresnel zone may be detected by a single trace, the feature can only be resolved if it is larger than the Fresnel zone.

Robin and others (1969) showed that while diffuse or

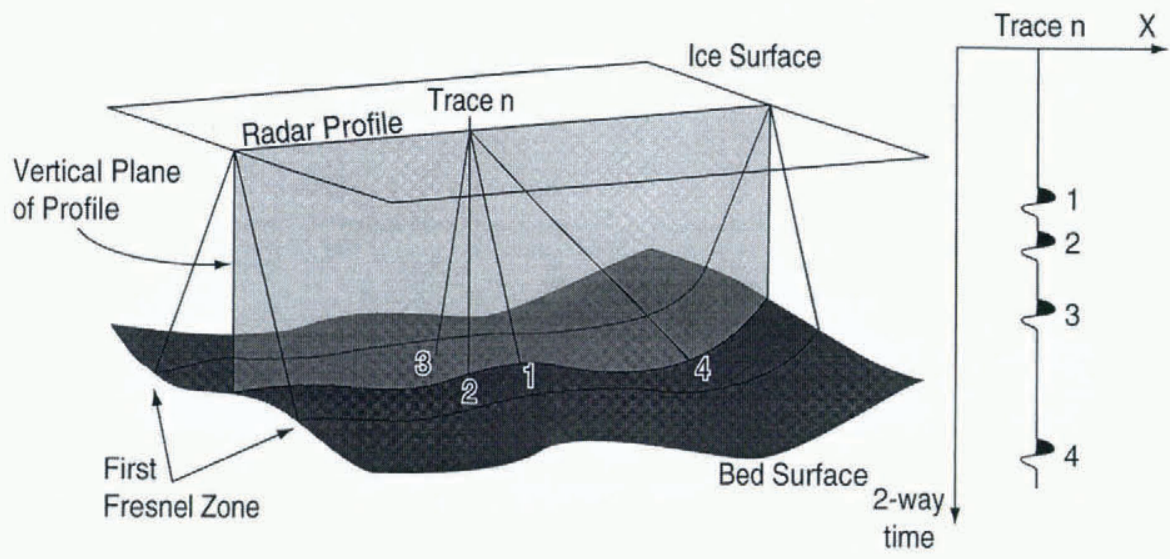

Fig. 1. Cartoon of echoes recorded by a single trace of a radio-echo sounding profile. 
rough reflecting surfaces alter the reflected power, the Fresnel zone does not change. Reflecting surfaces with roughness length-scales that are smaller than the Fresnel zone will affect detection but not resolution.

The radius of the Fresnel zone for a single trace varies non-linearly with distance between the reflecting surface and the radio-echo sounding equipment. Thus, the minimum size of a resolvable feature at the glacier bed increases non-linearly with glacier thickness. As stated earlier, by using the data from adjacent traces, migration has a focusing effect on the transmitted signal. In order to determine the effects of migration on resolution, a synthetic radio-echo sounding profile was created and migrated. The results of the migration were compared to the original synthetic bed topography.

The geometry of the synthetic radio-echo sounding profile is shown in Figure 2a. The ice surface is flat, the $300 \mathrm{~m}$ thick ice is electrically transparent (no attenuation or scattering) and the bed surface is a perfect reflector with a series of rectangular bumps of increasing length. The synthetic radar profile in Figure $2 \mathrm{~b}$ shows how a $5 \mathrm{MHz}$ radar would image the synthetic bed surface if the trace spacing were $5 \mathrm{~m}$. Note that the imaging principle commonly used to plot such data does not produce an image that resembles the original synthetic surface. The same frequency-wavenumber migration routine is used on the synthetic data as

a

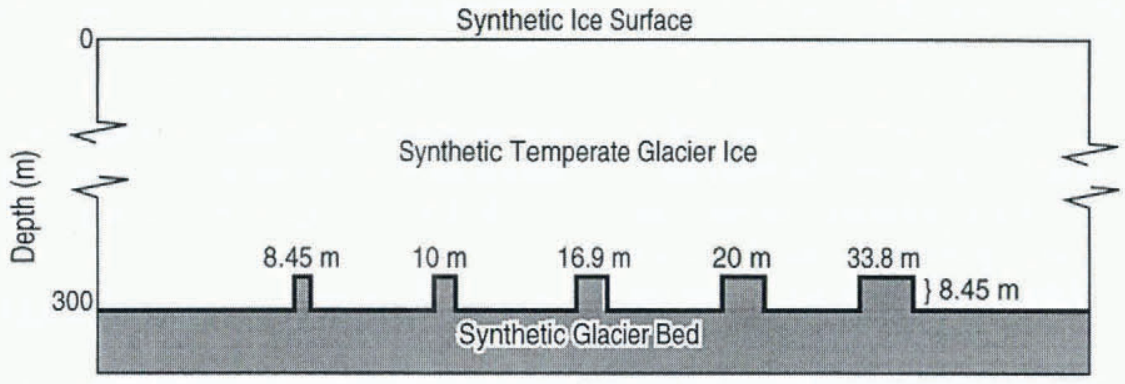

b

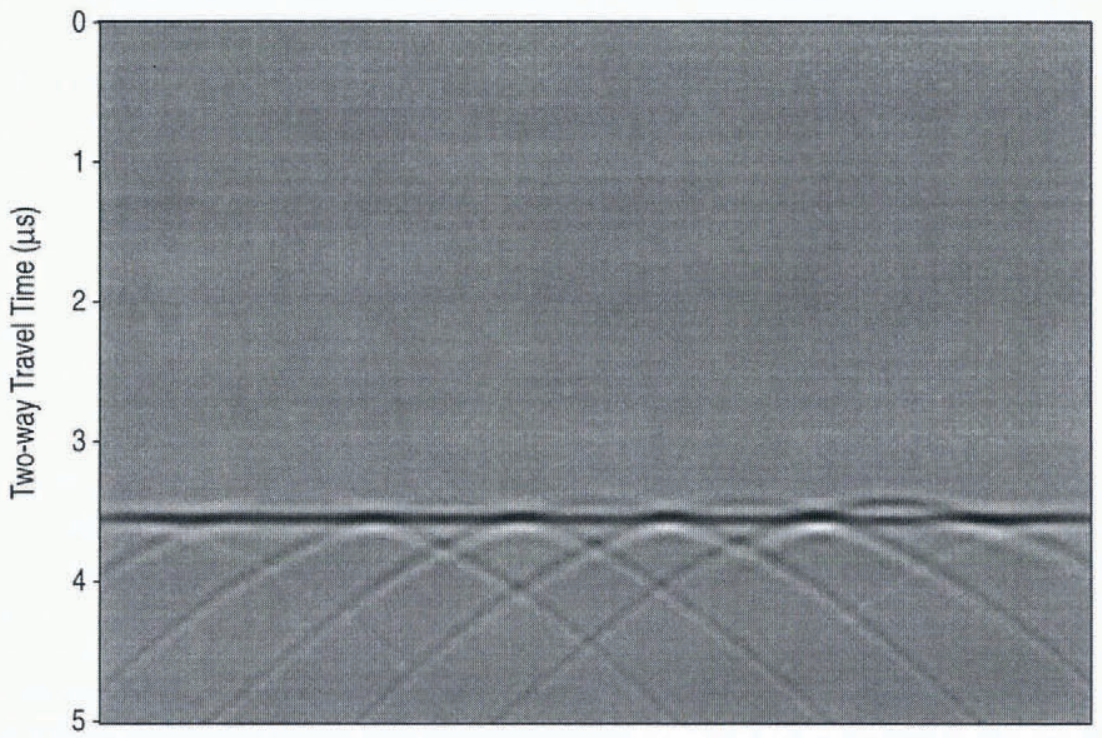

C

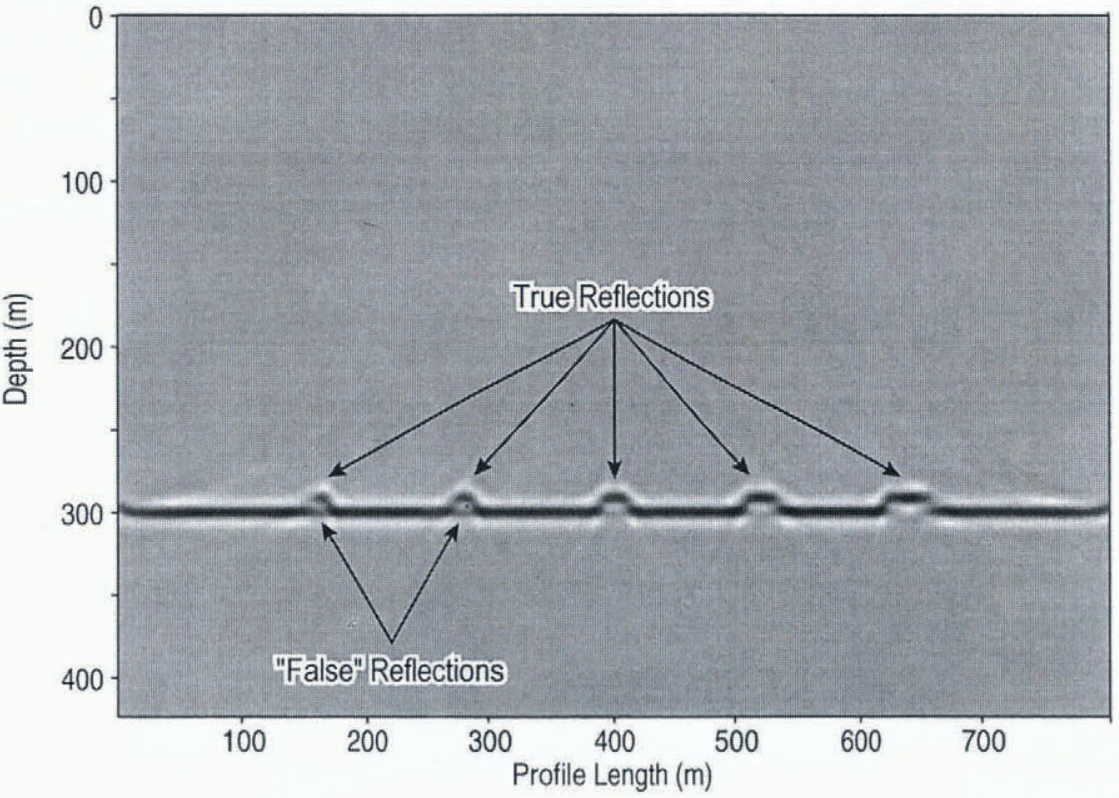

Fig. 2. (a) Bed geometry used to create a synthetic $5 \mathrm{MHz}$ radio-echo sounding profile. (b) Synthetic radio-echo sounding produced from the geometry in $(a)$. (c) Results of migrating the synthetic profile. Note that features smaller than $\lambda / 2$ are not resolved. 
was used for the Worthington Glacier data. As shown in Figure $2 \mathrm{c}$, migration alters the data so that the imaging principle will better represent the true synthetic glacier bed.

Due to the reflection geometry, migration can only resolve angles less than $45^{\circ}$, so the vertical edges of the bumps in Figure 2c are migrated to $45^{\circ}$ slopes (Chun and Jacewitz, 1986). The surface of the largest bump (33.8 $\mathrm{m}$ or $\lambda$ in length) has been clearly resolved. There is a single horizontal reflection from the surface of this large bump, clearly showing the feature's size and shape. The same is true for all bumps broader than $\lambda / 2$. Migration was unable to completely resolve the $10 \mathrm{~m}$ bump, as there appear to be two parallel horizontal reflectors. All bumps smaller than $\lambda / 2$ show two horizontal reflectors rather than the single reflector expected from the true bed geometry. Based on this experiment, the resolution of migrated profiles is $\lambda / 2$, as opposed to the depth-dependent Fresnel zone used to define the resolution of a single unmigrated trace.

The Fresnel zone defines the resolution of a single trace. When a profile of traces is migrated, the additional data of the adjacent traces can be used to improve the resolution of the entire profile (Yilmaz, 1987). The synthetic radio-echo sounding experiment has been repeated for ice thicknesses of $100-500 \mathrm{~m}$ with no changes to the results. From these results it is concluded that when signal losses due to attenuation, scattering and reflection are ignored, the $\lambda / 2$ resolution of a radio-echo sounding system is independent of depth. For a real glacier system, signal losses are present, but affect only the detection limits of the radio-echo sounding system. Therefore, any detectable feature with horizontal scale larger than $\lambda / 2$ can be resolved, independent of the distance between the transmitter and the feature.

\section{TWO-DIMENSIONAL VS THREE-DIMENSIONAL RADAR SURVEYS}

Most radio-echo sounding surveys of large ice sheets are conducted over many kilometers where the ice and bed surfaces do not change dramatically with respect to the length of the profile. Radio-echo sounding surveys of valley glaciers are complicated by the three-dimensional geometry of the glacier system. Unlike large ice sheets, the ice surface of a valley glacier is often steep, as are the valley walls and glacier bed. The proximity of the valley walls can produce reflections that are recorded by the radio-echo sounding system even when located in the center of the glacier.

Let us now consider the assumptions involved in migrating a single radio-echo sounding profile made up of a series of traces recorded at regular intervals across a valley glacier. Two-dimensional migration makes two critical assumptions: (1) all reflecting surfaces are located along the profiles, i.e. no reflections are recorded from surfaces to either side of the profile, and (2) all apparent reflector slopes used in migration are in the direction of the profile (Claerbout, 1985; Yilmaz, 1987). The topography of most valley glaciers is complex and three-dimensional, so that it is clear that the assumptions of two-dimensional migration are rarely met (Fig. 1). Therefore, interpretations based on the results of two-dimensional migration of a single profile from a valley glacier can be incorrect.

In order to map the complex geometry of a valley glacier, a three-dimensional radio-echo sounding survey is necessary. An array of closely spaced radio-echo sounding traces can be processed as a three-dimensional dataset where fully three-dimensional migration routines can accommodate reflections from any location. Two-pass twodimensional migration is a pseudo-three-dimensional migration routine that is an efficient alternative to the complexities involved in a fully three-dimensional migration (Claerbout, 1985; Yilmaz, 1987).

Two-pass migration involves two passes of a two-dimensional migration routine. The profile is recorded across the dominant topography, so most of the recorded reflections that are not directly below the trace location will be along the profile plane. The first migration pass processes the profiles across the expected dominant topography of the surveyed region to migrate the reflections located within the profile plane. As a result, the reflections originating within the profile plans have been placed in their appropriate locations. Reflections originating to either side of the cross-glacier profile plane will not be much affected by the first pass of migration (Yilmaz, 1987). In order to correct the off-profile reflectors, the cross-glacier migrated profiles are then migrated a second time in the orthogonal direction to place these off-profile reflections in their proper locations. A single migration pass can only correct reflections within the profile plane. The two-pass routine reduces the effects of reflectors located on either side of the profile, as well as within the profile plane, and improves the accuracy and resolution of the imaging principle.

\section{FIELD METHODS TO MAXIMIZE RADAR SURVEY RESOLUTION}

Field procedures are critical to the final resolution and accuracy of a radio-echo sounding survey. Trace and profile spacing less than $\lambda / 4$ will avoid the problems of spatial aliasing. Processing routines are made much simpler if the traces of the profile array are laid out in an orthogonal grid. Field identification of bed reflectors is usually easier if the profiles are recorded across the dominant topography (Yilmaz, 1987). For most valley glaciers, the dominant topography is the valley itself, so profiles should be recorded in the crossglacier direction.

Trace locations, particularly elevations, should be determined as accurately as possible because they define initial reflector slopes that are crucial to migration accuracy (Yilmaz, 1987). Trace stacking is used to reduce noise in the recorded signals by averaging multiple traces at a single location. Stacking can be done in the field or during later processing.

\section{PROCESSING STEPS FOR RADAR DATA}

The first step of processing is to assign trace-location coordinates to the radio-echo sounding traces. If not done in the field, multiple traces recorded at a single location are stacked to produce a single trace for each trace location. Static correction calculations account for elevation differences between traces, antenna separation between the transmitter and receiver and any near-surface velocity corrections (such as variable firn depth) that are necessary before migration (Yilmaz, 1987). Low-pass and high-pass filters remove noise from the traces.

The two-pass migration is used to alter the dataset so that the imaging principle better represents the true reflect- 
ing topography. The first two-dimensional migration is applied across the dominant topography. The migrated traces are then sorted into profiles oriented in the orthogonal direction, the down-glacier direction for a valley glacier. The reoriented migrated profiles are then migrated a second time with the same two-dimensional migration routine (Claerbout, 1985; Yilmaz, 1987).

\section{CASE-STUDY: RADAR SURVEY OF WORTHING- TON GLAGIER, ALASKA}

Worthington Glacier is a temperate valley glacier in southcentral Alaska (Fig. 3). Ongoing research of the three-dimensional flow field of the glacier required an accurate high-resolution map of the glacier bedrock surface (Pfeffer and others, 1994; Harper and Humphrey, 1995; Harper and others, 1996). During the summer of 1996, 18 radio-echo sounding profiles were recorded in the ablation zone with a $5 \mathrm{MHz}$ system (Narod and Clarke, 1994). The profiles were $20 \mathrm{~m}$ apart and made up of traces recorded every $5 \mathrm{~m}$. Trace locations were determined by optical surveying to within $0.5 \mathrm{~m}$. The profiles ranged from 565 to $725 \mathrm{~m}$ long for a total

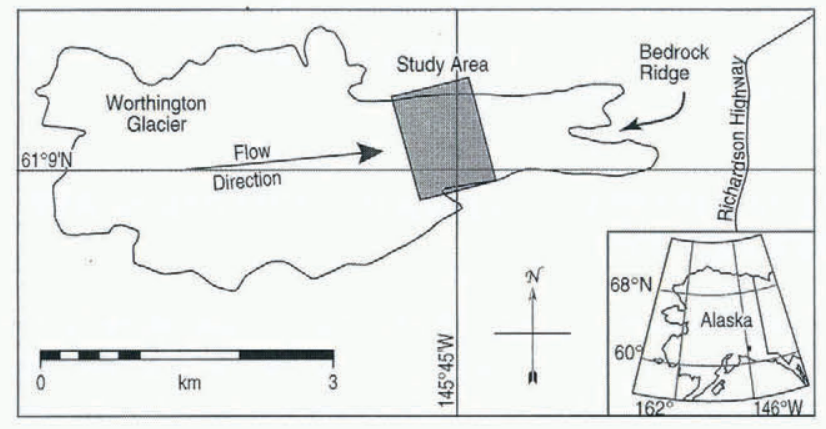

Fig. 3. Location of the study site on Worthington Glacier, Alaska.

of just under 2300 traces (Fig. 4). At each location, 32 traces were stacked by the oscilloscope to produce a final trace that was recorded to a laptop computer.

Static corrections were calculated for the trace elevations and the trigger delay caused by the $20 \mathrm{~m}$ separation between the transmitter and receiver. Static calculations and migrations assumed a $33.8 \mathrm{~m}$ wavelength based on a

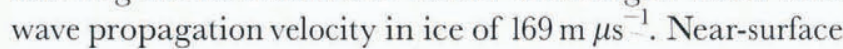
velocity variations due to the $2 \mathrm{~m}$ snow depth were ignored. Recorded frequencies below $4 \mathrm{MHz}$ and above $7.5 \mathrm{MHz}$ were removed with a digital band-pass filter. Figure 5a shows profile 10 of the profile array ready for two-pass migration.

A frequency-wavenumber migration routine was used for the two-pass migration (Cohen and Stockwell, 1996). The profiles were migrated first in the cross-glacier direction. Figure $5 \mathrm{~b}$ shows profile 10 after the first pass of twodimensional migration. The 4:1 profile-to-trace spacing required alterations to the ideal two-pass migration routine. The $20 \mathrm{~m}$ cross-glacier profile spacing exceeds $\lambda / 4$, so spatial aliasing was expected in that direction. Using the migrated traces, synthetic traces were interpolated to reduce the cross-glacier profile spacing to $5 \mathrm{~m}$. The interpolated traces were added for computational convenience, and do not eliminate spatial aliasing.

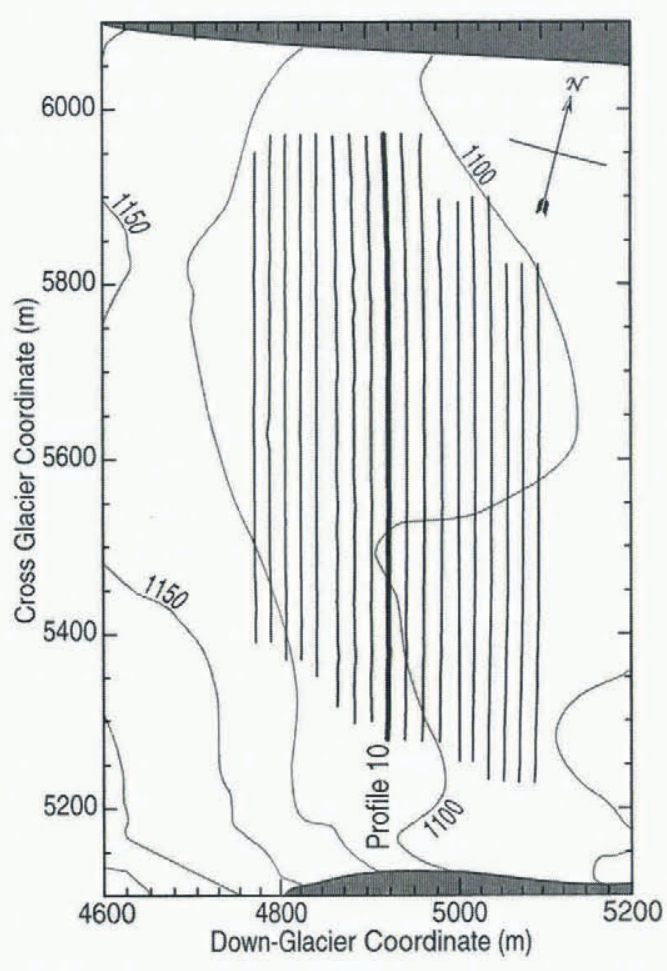

Fig. 4. Arrangement of the radio-echo sounding profile array on Worthington Glacier. Profiles were recorded in the crossglacier direction.

The migrated and interpolated traces were then oriented to produce down-glacier profiles. The orthogonal grid of traces established in the field greatly simplified this procedure. The down-glacier profiles were migrated using the same two-dimensional frequency-wavenumber migration routine. The interpolated traces were discarded and the two-pass migrated profiles reoriented back to crossglacier profiles for interpretation as shown in Figure $5 \mathrm{c}$.

The two-way travel times of the reflections were converted to depths using the wave-propagation velocity of $169 \mathrm{~m} \mu \mathrm{s}^{-1}$ in ice. The bed reflectors were identified in the two-pass migrated profiles and digitized to create a map of the glacier bed surface. The $20 \mathrm{~m}$ profile spacing limits the resolution of the final bed-surface map to $20 \mathrm{~m}$ in the downglacier direction. As shown earlier, migration establishes the resolution in the cross-glacier direction to $\lambda / 2$ or $16.9 \mathrm{~m}$ for a $5 \mathrm{MHz}$ radio-echo sounding system. Since the effects of the interpolated traces are not well known, the entire subglacial bed-surface map was smoothed to a resolution of $20 \mathrm{~m} \times 20 \mathrm{~m}$ by means of a $20 \mathrm{~m} \times 20 \mathrm{~m}$ Gaussian-weighted averaging window. The final surface is shown as a contour map and a wire-frame surface in Figure 6. The detailed topography in the maps represents the best resolution of the radio-echo sounding system based on field and processing procedures.

The glacier thickness was calculated from the glacier bed-surface map and the trace-location coordinates. The ice thicknesses as determined by radio-echo sounding were then compared to borehole measurements of the ice thickness made in 1994. It was found that the radio-echo sounding measurements of ice thickness were within $\lambda / 4(8.45 \mathrm{~m})$ of the borehole measurements.

The resolution of the subglacial bed-surface map could be improved by reducing the profile spacing to less than $\lambda / 4$. This would remove the problem of spatial aliasing, and improve the data density in the down-glacier direction. How- 

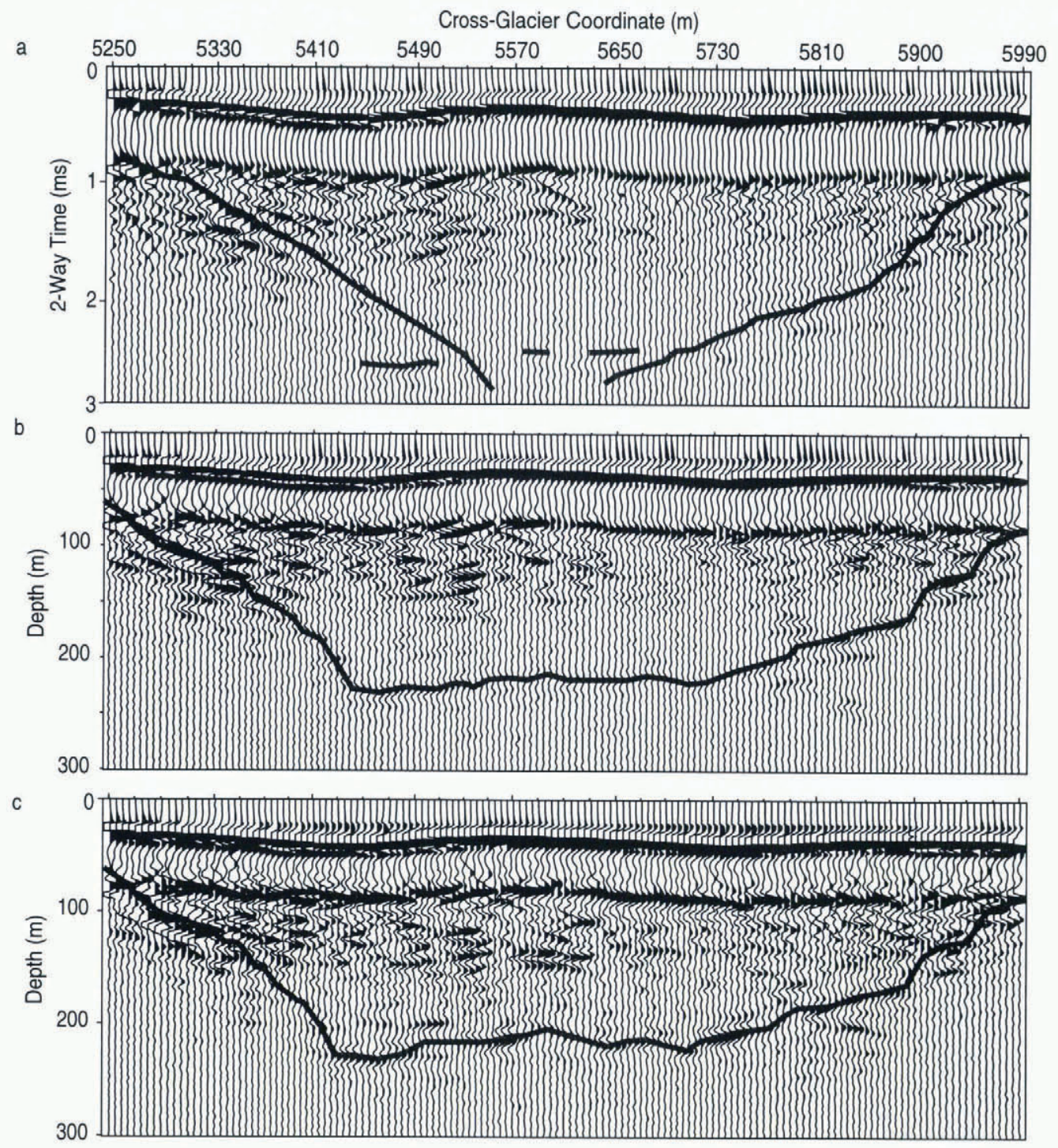

Fig. 5. (a) Profile 10 ready for two-pass migration after static corrections. Interpreted bed reflections have been highlighted. (b) Results of the first pass of two-dimensional migration in the cross-glacier direction. (c) Profile 10 after the second migration, this time in the down-glacier direction. Note the differences in the geometry of the bed reflector.

ever, the best obtainable resolution for a temperate glacier will be $\lambda / 2 \times \lambda / 2$, or $16.9 \mathrm{~m} \times 16.9 \mathrm{~m}$ for a $5 \mathrm{MHz}$ radio-echo sounding system.

\section{RESULTS}

The resolution of a radio-echo sounding survey is determined by the wavelength of the system as well as field and processing techniques. The following field techniques are critical to the obtainable resolution from a radar survey:

trace and profile spacing must not be more than $\lambda / 4$

the three-dimensional surface locations of traces must be accurately measured

orient the profiles across the dominant topography (cross-glacier for most valley glaciers)

stack multiple traces at each location.

If these criteria are not considered in the field, processing cannot compensate for the resulting loss of resolution. An additional consideration that will ease the processing steps is to arrange the profile array so that the traces form an orthogonal grid.
Processing the profiles alters the data so the subglacial bed reflector can be easily interpreted from the imaging principle. Two-pass migration is necessary for radio-echo sounding surveys of complicated three-dimensional topography such as valley glaciers. Two-pass migration and the high density of data results in $\lambda / 2 \times \lambda / 2$ resolution as long as the reflectors can be detected. The following processing steps should be used to create a map of the subglacier bed surface:

static corrections: ice-surface elevation, antenna separation, near-surface velocity corrections

filter the profiles to remove long and short wavelength noise

two-pass migrate the profiles: two-dimensional migration across dominant topography, then two-dimensional migration in orthogonal direction

interpret profiles to produce map of reflector surface, smooth interpreted surface to resolution limits $(\lambda / 2 \times \lambda / 2)$.

If all of the field and processing techniques are followed, the maximum resolution is $\lambda / 2 \times \lambda / 2$. Application of these techniques to Worthington Glacier has produced an accurate map with $20 \mathrm{~m} \times 20 \mathrm{~m}$ resolution that will be useful for a variety of glacier research. 
a

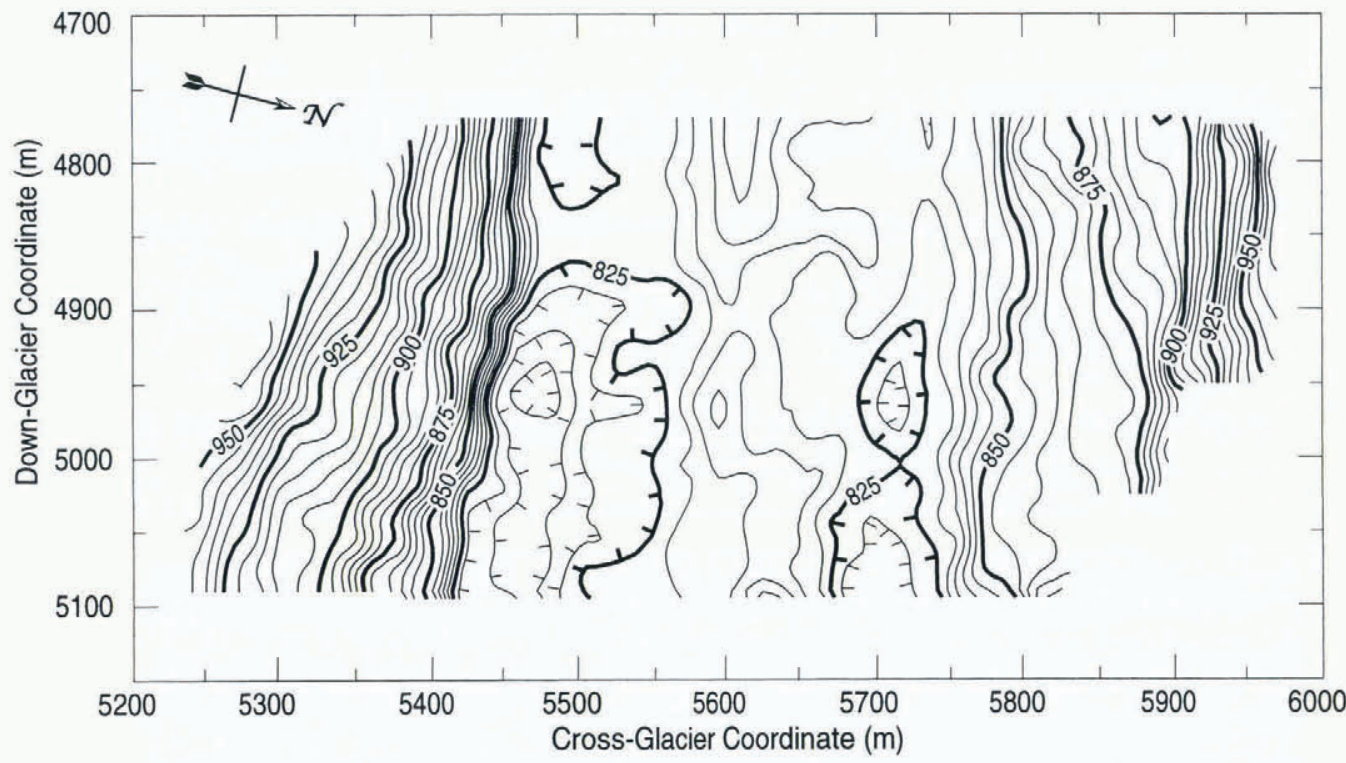

b

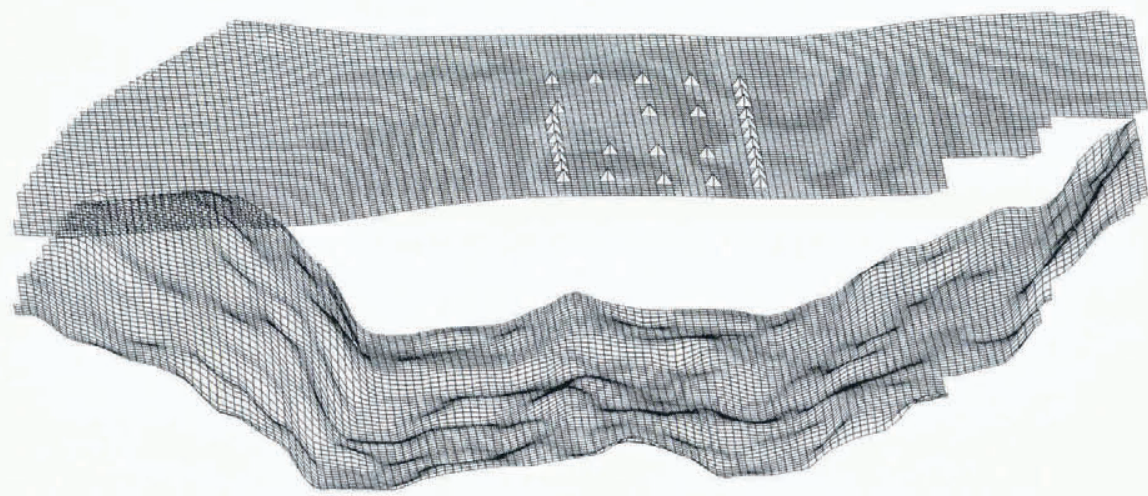

Fig. 6. Final map of the subglacial bed surface after $20 \mathrm{~m} \times 20 \mathrm{~m}$ smoothing, shown as (a) contour map with $5 \mathrm{~m}$ contours and (b) three-dimensional wire-frame image of the ice and bed surfaces. Bumps on the ice surface represent locations of boreholes.

\section{ACKNOWLEDGEMENTS}

The authors much appreciate the critical reviews of $\mathrm{H}$. Björnsson and an anonymous reviewer. This work was funded through U.S. National Science Foundation grants OPP-9122916 and OPP-9531450.

\section{REFERENCES}

Arcone, S. A., D. E. Lawson and A. J. Delaney. 1995. Short-pulse radar wavelet recovery and resolution of dielectric contrasts within englacial and basal ice of Matanuska Glacier, Alaska, U.S.A. f. Glaciol., 41 (137), 68-86.

Björnsson, H. 1981. Radio-echo sounding maps of Storglaciären, Isfallsglaciären and Rabots glaciär, northern Sweden. Geogr. Ann., 63A(3-4), 225-231.

Björnsson, H. and 6 others. 1996. The thermal regime of sub-polar glaciers mapped by multi-frequency radio-echo sounding. 7. Glaciol., 42(140), 23-32.

Bogorodsky, V.V., C. R. Bentley and P. E. Gudmandsen. 1985. Radioglaciology. Dordrecht, etc., D. Reidel Publishing Co.

Brown, C. S., L. A. Rasmussen and M. F. Meier. 1986. Bed topography inferred from airborne radio-echo sounding of Columbia Glacier, Alaska. U.S. Geol. Surv. Prof. Pap. 1258-G.

Chun, J.H. and C. A. Jacewitz. 1981. Fundamentals of frequency domain migration. Geophysics, 46 (5), 717-733.

Claerbout, J. F, 1985. Imaging the Earth's interior. Oxford, Blackwell Scientific Publications.
Cohen, J. K. and J.W. Stockwell. 1996. CWP/SU: seismic Unix release 29: a free package for seismic research and processing. Golden, CO, Colorado School of Mines. Center for Wave Phenomena.

Harper, J. T. and N. F. Humphrey. 1995. Borehole video analysis of a temperate glacier's englacial and subglacial structure: implications for glacier flow models. Geology, 23(10), 901-904.

Harper, J.T., N. F. Humphrey, W.T. Pfeffer and B. C. Welch. 1996. Short wavelength variations in the horizontal velocity field of a valley glacier. CRREL Spec. Rep. 96-27, 41-48.

Harrison, C. H. 1970. Reconstruction of subglacial relief from radio echo sounding records. Geophysics, 35, 1099-1115.

Jacobel, R.W., A. M. Gades, D. L. Gottschling, S. M. Hodge and D. L. Wright. 1993. Interpretation of radar-detected internal layer folding in West Antarctic ice streams. f. Glaciol., 39(133), 528- 537.

Narod, B. B. and G. K. C. Clarke. 1994. Miniature high-power impulse transmitter for radio-echo sounding. f. Glaciol., 40(134), 190-194.

Pfeffer, W. T., N. F. Humphrey, D. B. Bahr, J. Harper, B. Raup and B. Welch. 1994. Observed velocity structure at depth in Worthington Glacier, Alaska. [Abstract.] EOS, 75(44), Supplement, 222.

Robin, G. de Q., S. Evans and J. T. Bailey. 1969. Interpretation of radio echo sounding in polar ice sheets. Philos. Trans. R. Soc. London, Ser. A, 265(1166), 437-505.

Smith, B. M. E. and S. Evans. 1972. Radio echo sounding: absorption and scattering by water inclusions and ice lenses. f. Glaciol., 11 (61), 133-146.

Watts, R. D. and A.W. England. 1976. Radio-echo sounding of temperate glaciers: ice properties and sounder design criteria. f. Glaciol., 17(75), $39-48$.

Yilmaz, Ö. 1987. Seismic data processing. Tulsa, OK, Society of Exploration Geophysicists. (Investigations in Geophysics 2.) 